\title{
A SOBERANIA ALIMENTAR E A RELEITURA DO CONCEITO DE REGIÃO PELA GEOGRAFIA
}

\author{
Estevan Leopoldo de Freitas Coca \\ Professor Adjunto A - Universidade Federal de Alfenas \\ estevan.coca@unifal-mg.edu.br
}

\begin{abstract}
RESUMO
Com o processo de globalização neoliberal e a emergência de um suposto mundo sem fronteiras, a região - um dos primeiros conceitos trabalhados pela Geografia - parece perder o sentido. Contudo, como parte do caráter desigual do desenvolvimento capitalista, ao mesmo tempo se manifestam espacialmente a igualização e a diferença, o que faz com que a região mude de significado, porém, não deixe de existir. No presente texto, problematizamos essa assertiva tomando por referência a proposta alternativa de soberania alimentar, a qual tem sido defendida pela coalizão internacional La Via Campesina desde meados da década de 1990 como uma alternativa ao regime agroalimentar corporativo. Como parte dos procedimentos metodológicos, fizemos um amplo levantamento bibliográfico e documental e realizamos trabalhos de campo no Brasil e no Canada. A principal conclusão a que chegamos é que a soberania alimentar, ao defender o direito e dever de cada povo controlar o seu próprio processo de alimentação, coloca-se como um dos componentes do Novo Regionalismo, acentuando a dimensão espacial da propriedade do ser regional.
\end{abstract}

Palavras-chave: Região. Novo Regionalismo. Soberania alimentar.

\section{FOOD SOVEREIGNTY AND A RE-EXAMINING OF THE CONCEPT OF REGION TROUGH GEOGRAPHY}

\begin{abstract}
With the process of neoliberal globalization and the emergence of a supposed world without borders, the region - one of the first concepts addressed by Geography - seems to lose its meaning. However, as part of the unequal nature of capitalist development, equalization and difference are manifested spatially at the same time, which leads the notion of region to change its meaning, but, nevertheless, it does not cease to exist. In this paper, we discuss this assertion by exploring the alternative proposal of food sovereignty, which has been defended by the international coalition La Vía Campesina since the mid-1990s as an alternative to the corporate agri-food regime. As part of the methodological procedures, we have carried out a broad bibliographical and document review as well as fieldwork in Brazil and Canada. The main conclusion reached is that food sovereignty, by defending the right and duty of all people to control their own food process, is one of the components of the new regionalism, emphasizing the spatial dimension of the regional being.
\end{abstract}

Keywords: Region. New Regionalism. Food sovereignty.

\section{INTRODUÇÃO}

Desde a década de 1970, diversas mudanças têm sido presenciadas na organização da economia global, gerando impactos multidimensionais e multiescalares. Pode-se citar a transição da rigidez do fordismo (presente na modernidade) para o modelo de acumulação flexível (presente na pós-modernidade) (HARVEY, 1992); a ocorrência da revolução telemática, por meio de inovações como os cabos de fibra óptica, as imagens de satélite, a internet, a telefonia móvel, a TV a cabo e outros (BENKO, 2001; HARVEY, 2001); a globalização neoliberal e um forte discurso de eliminação das fronteiras materiais e imateriais (SASSEN, 2005; Van HOUTUM, 2005). Apoiados nesse contexto, diversos trabalhos pontuaram a "morte" do conceito de região (MOREIRA, 2007; OLIVEIRA, 1987, por exemplo), o qual tradicionalmente vinha sendo trabalhado na Geografia por meio da diferenciação areal, variando os métodos para atingir esse objetivo (HAESBAERT, 2005; LENCIONI, 1999). Nesses casos, o entendimento é que, na atualidade, a principal forma de organização da sociedade se dá por meio das redes, sendo a fluidez um

\begin{tabular}{llllll}
\hline Caminhos de Geografia & Uberlândia - MG & v. 19, n. 68 & Dez/2018 & p. 372-388 & Página 372
\end{tabular}


dos mais importantes elementos do processo de extração da mais-valia, ao mesmo tempo em que a região é lida como sinônimo de fixidez.

Com esse trabalho, destacamos que, apesar de a globalização neoliberal contribuir para a homogeneização do espaço, se apoiando numa série de novas tecnologias que organizam o globo em torno do capital financeiro (HARVEY, 2001; PAULA et al., 2015) - fato que modifica até mesmo as atribuições do Estado-Nação - ela também gera a diferenciação espacial (SANTOS, 2000; SANTOS e SILVEIRA, 2001), pois os lugares, grupos e sujeitos não são afetados por ela com a mesma intensidade (MASSEY, 2009). Isso pode ser percebido por meio de elementos como a emergência de "regiões que ganham" e "regiões que perdem" (BENKO e LIPIETZ, 1994), haja vista que uma das características do neoliberalismo tem sido a saída de cena do Estado Planejador, característico da macroeconomia keynesiana (McMICHAEL, 2000) e a articulação de propostas de desenvolvimento no interior dos Estados-Nação de modo descentralizado (ALVES, 2003; ARRETCHE, 1996; CARGNIN, 2016), rendendo aquilo que Vainer (2007) chama de "paroquialismo mundializado".

Sob esse contexto, destacamos aqui o exemplo da soberania alimentar para reconhecer que na atualidade a região muda de sentido, porém, não deixa de existir. Demonstramos que desde sua proposição pela coalizão global La Via Campesina, em 1996, a soberania alimentar tem chamado a atenção para a necessidade de cada povo controlar o seu próprio processo de alimentação, levando em consideração fatores como a prioridade às agriculturas camponesa e indígena, a questão de gênero, a inserção dos jovens na produção e comercialização de alimentos, o acesso dos pequenos agricultores aos mercados institucionais e principalmente, a produção sob bases agroecológicas (COCA, 2016a, 2016b; PATEL, 2012; WITTMAN et al., 2011). Nesse sentido, emergem uma série de ações no campo e na cidade com forte caráter local (ROMAN-ALCALÁ, 2013; SONNINO, 2010), as quais visam se posicionar como alternativas ao regime agroalimentar corporativo que se organiza por meio de dinâmicas globais desempenhadas por grandes empresas do setor agroalimentar (MARSDEN, 2013; McMICHAEL, 2016). Esses são elementos do Novo Regionalismo, entendido nesse trabalho como a propriedade do ser regional, estando assim, em constante re-articulação com a globalização (HAESBAERT, 1999).

Para essa análise, adotamos dois procedimentos metodológicos centrais: i) levantamento e análise de materiais acadêmicos e institucionais sobre os temas debatidos no texto, especialmente a abordagem geográfica sobre a região e a proposta alternativa de soberania alimentar. Esses documentos foram organizados tematicamente no software de referenciamento bibliográfico Mendeley e; ii) trabalhos de campo realizados entre março de 2013 e julho de 2016 nos territórios da cidadania do Cantuquiriguaçu (estado do Paraná) e do Pontal do Paranapanema (estado de São Paulo), no Brasil e na região Metropolitana de Vancouver (província de British Columbia), no Canadá. Com isso, foi possível analisar as novas dinâmicas regionais tendo por referência ações que se apoiam na bandeira da soberania alimentar. Enfatizamos elementos vindos do campo e da cidade para desenvolver a presente discussão, além de considerarmos o protagonismo de produtores e de consumidores de alimentos na busca pela construção de estratégias alternativas ao regime agroalimentar corporativo.

Dividimos o trabalho em três partes, além da presente introdução e das considerações finais. Na primeira, fazemos uma leitura da trajetória do conceito de região na Geografia com ênfase na contribuição do marxismo. Retomando os paradigmas geográficos da baixa modernidade, da modernida industrial e da pós-modernidade, discutimos a pertinência de considerar a permanência do conceito de região para a interpretação da realidade atual ou não. Na segunda, fazemos uma discussão sobre a proposição da soberania alimentar, enfatizando a contribuição que ela oferece para a interpretação contemporânea da região. Demonstramos como, no contexto de globalização neoliberal, a soberania alimentar parte do entendimento de que a solução para problemas globais deve partir da escala local. Para isso, abordamos exemplos de articulação em favor da soberania alimentar que enfatizam a emergência de um Novo Regionalismo, considerando o protagonismo de grupos e movimentos do campo e da cidade. Na terceira, trazemos alguns exemplos do Brasil e do Canadá que denotam a relação da soberania alimentar com a produção da diferencialidade como parte das contradições inerentes à globalização neoliberal.

\section{A TRAJETÓRIA DO CONCEITO DE REGIÃO NA GEOGRAFIA}

No livro "Para onde vai o pensamento geográfico", Moreira (2006) explicita que até meados do século XX, o conceito de região teve centralidade na Geografia, mesmo que sendo apresentado por meio de diferentes proposições teórico-metodológicas. Seguindo a classificação do autor, a história do pensamento geográfico pode ser dividida em três grandes paradigmas: o holista, da baixa modernidade (séculos XVIII e XIX); o fragmentário; da modernidade industrial (séculos XIX e XX) e o atual (pós-modernidade), que

\begin{tabular}{llllll}
\hline Caminhos de Geografia & Uberlândia - MG & v. 19, n. 68 & Dez/2018 & p. 372-388 & Página 373
\end{tabular}


visa recuperar o holismo. Os paradigmas são formados por bases filosóficas variadas e reverberam uma visão de mundo que se aplica na própria interpretação da ciência. Tomamos essa linha de interpretação para retratar o uso do conceito de região pela Geografia e discutir a possibilidade de considera-lo como capaz de explicar a realidade atual ou não.

Apesar de a Geografia existir desde a Grécia Antiga, sua versão moderna surgiu em meados do século $\mathrm{XVIII}$, quando ela se organiza em torno de um paradigma holista, ou seja, homem e natureza não eram abordados de modo dicotômico e sim como parte de uma totalidade. Por meio, primeiramente da abordagem descritiva sobre as paisagens, a Geografia se desevolveu através do método corográfico.

Nesse período, as bases do conhecimento geográfico são estruturadas pelas contribuições de Kant, no plano epistemológico e Foster, no plano teórico-metodológico (MOREIRA, 2006). Todavia, a sistematização da Geografia se deu com a produção de Humboldt (1875) e Ritter (1865). Enquanto o primeiro construiu uma perspectiva holística que partia do inorgânico para trabalhar o orgânico e 0 humano, o segundo teve no conceito de região sua proposição central. Assim, em Ritter (1865) destaca-se a concepção de individualidade regional, sendo que a região é abordada como um método. Prevalece a perspectiva corológica, de modo que, partindo da paisagem, a região é tomada como elemento de diferenciação espacial.

Todavia, com a emergência da modernidade industrial em meados do século XIX, a Geografia passaria a ser fortemente influenciada pelo positivismo, o que repercutiria de modo direto na abordagem sobre as regiões. Como um dos princípios do positivismo é a compartimentação do saber, de imediato, a Geografia abandonou o holismo e se dividiu em diversos ramos (MOREIRA, 2006). Primeiramente, essa divisão do saber geográfico se deu nos trabalhos que partiam do inorgânico e depois, atingiu também os trabalhos relacionados ao orgânico e ao humano. Posteriormente, esses ramos seriam parcialmente reagrupados, dando origem, primeiramente à Geografia Regional e depois às geografias Física e Humana, contudo, o caráter positivista permaneceu.

Assim, num primeiro momento, o abandono do holismo foi acompanhado pelo abandono do conceito de região. Num segundo momento, a região foi retomada como conceito capaz de explicar a realidade, porém, dentro de uma perspectiva que por ser positivista, não dava ênfase à dinamicidade do espaço. É nesse contexto que Moreira (2006) pontua consistir o grande choque de ideias da Geografia da modernidade industrial, qual seja, o debate entre a perspectiva de região de La Blache (1954) (caráter uniqueísta) e de Hettner (2000) (caráter relacional). Para o primeiro, a região era entendida como a união entre o físico e o humano, sendo que por meio dela era possível destacar as diferenças entre os lugares, a exemplo do que foi feito por ele e seus seguidores em relação às pays francesas. O segundo representou um retorno a Ritter, porém, não entendeu a região como um método e sim como uma relação, reproduzindo assim, a concepção científica neokantista que ganhava grande relevo naquele momento (LENCIONI, 1999).

Ainda na modernidade industrial, não podemos deixar de destacar a influência exercida pelo neopositivismo, construindo a Geografia Teorético-Quantitativa ou New Geography. Essa se apoiou sobremaneira nas proposições do Círculo de Viena, o qual, conforme destacado no documento "A concepção científica do mundo", visava romper com o conhecimento metafísico e teológico, seguindo uma perspectiva empirista e, assim, constituir uma ciência unificada (HAHN et al., 1929). De tal modo, na Geografia daquele período, os neopositivistas entendiam que o conceito de região, ao valorizar a diversidade espacial, apresentava um obstáculo na busca por dar a essa disciplina um verdadeiro rigor científico (HAESBAERT, 2005). Por isso, as abordagens da região tecidas nesse contexto valorizavam mais os aspectos matemáticos e de classificação de áreas, não enfatizando a dinâmica e a processualidade do espaço, como pode-se constatar no trabalho de Grigg (1973).

Em meados do século XX, uma série de fatores como a crise ambiental, o movimento feminista, as constestações à Guerra do Vietnã e outros, fez com que a ciência buscasse novas explicações para um mundo em rápida mudança (MOREIRA, 2011). Devido a isso, na Geografia se constatou a busca pela substituição do positivismo por abordagens dotadas de maior consistência crítica (SANTOS, 1986). Nesse bojo, emerge a Geografia atual, que se caracteriza pela busca pela retomada do holismo e superação da fetichização do espaço (LENCIONI, 1999; MOREIRA, 2006). Destacam-se duas correntes filosóficas, a fenomenologia e o marxismo.

A fenomenologia tem seus fundamentos em Husserl (1976), apresentando-se como a ciência das essências e baseando-se no método da redução. Todavia, na Geografia, o destaque é a fenomenologia existencial, de Merleau-Ponty (1999), que enfatiza a subjetividade e visa ir além do método redutivo. A região é um conceito muito pouco trabalhado pela fenomenologia, porém, merece destaque a contribuição

\begin{tabular}{llllll}
\hline Caminhos de Geografia & Uberlândia - MG & v. 19, n. 68 & Dez/2018 & p. 372-388 & Página 374
\end{tabular}


de Frémont (1980), o qual visa reinterpretar o espaço, considerando-o como formado por hierarquias encaixadas. Assim, a região é vista pelo autor por meio da subjetividade, do pertencimento, da identificação etc. Não se destaca a construção social do espaço regional, pois a centralidade está no indivíduo.

No marxismo se encontram alguns dos mais acalorados debates sobre as dinâmicas regionais na atualidade. Num primeiro momento, visando ir além da Geografia positivista, foram produzidas leituras marxistas que desconsideravam o conceito de região. Um exemplo clássico é o de Lacoste (1988), que via na região um conceito-obstáculo, impedindo uma leitura do espaço por meio da sua processualidade. Entendia-se que a região escondia os conflitos, de modo que ao trabalhar com ela, o geógrafo via-se incapaz de produzir uma leitura que considerasse a luta de classes como elemento estrutural. Mesmo não vindo diretamente da Geografia, também é digna de nota a contribuição de Oliveira (1987), para quem o capitalismo gera uma homogeneização do espaço, tornando inviável a estruturação de propostas de desenvolvimento regional, fato marcante do fordismo.

Contudo, uma grande gama de trabalhos tecidos no marxismo tem buscado destacar o fato de que o desenvolvimento gerado pelo capitalismo não se dá de modo homogêneo no espaço, levando em consideração os efeitos diferenciais gerados pela divisão do trabalho. Nesse sentido, surge a possibilidade de se trabalhar a produção do espaço regional com base nas disputas entre as classes sociais.

Sobre isso, vale ressaltar que já em autores clássicos do marxismo, a diferenciação socioespacial ganhou importante relevo. Em Lênin (1982), por exemplo, o conceito de desenvolvimento desigual foi utilizado para explicar as diferenças no ritmo de crescimento de alguns importantes ramos industriais, ocasionando a concentração de riqueza por parte de alguns Estados-Nação. Trotsky (1985), por seu turno, ao analisar a Rússia pré-revolução bolchevique, trabalhou com o conceito de desenvolvimento desigual e combinado numa tentativa de explicar como determinadas sociedades podem chegar ao socialismo pulando etapas. De modo mais explícito, em "A Questão Meridional", Gramsci (1987) debateu o processo de unificação da Itália com base na produção da Questão Regional. O autor demonstrou que o processo de industrialização do país se deu de modo concentrado no Norte (rico), ao passo que o Sul permaneceu pobre e de características rurais. Contudo, à primeira vista causa estranhamento o fato de as oligarquias do Sul não terem se oposto à unificação do país com base na região do Piemonte, localizada no Norte. A explicação do autor é que isso se deu como um acerto de classes, de modo que as forças hegemônicas do Sul viam nesse consentimento uma possibilidade de se manter no poder.

Essas referências clássicas do marxismo foram importantes para a produção de interpretações do conceito de região que fossem além da fetichização do espaço (LENCIONI, 1999), deixando de considerálo como um a priori ou como um receptáculo. Assim, passou-se a trabalhar a região como expressão do desenvolvimento desigual gerado pelo capitalismo, o qual, conforme Smith (1988), gera ao mesmo tempo a igualização e a diferenciação, dando ênfase a uma dinâmica escalar complexa e dinâmica. A região não remete apenas a um espaço herdado, mas às dinâmicas socioespaciais.

A produção do geógrafo brasileiro Milton Santos $(1986,1988,1999)$ pode ser tomada como uma das mais importantes referências para o desenvolvimento dessa compreensão da permanência da região no contexto presente em que o capitalismo se articula por meio da globalização neoliberal. Para o autor, além da globalização que se apresenta como fábula e como perversidade, é possível falar de uma outra globalização, a qual é construída "de baixo para cima", visando romper com o status quo (SANTOS, 2000). A outra globalização parte do lugar, entendido como espaço da existência e da coexistência (SANTOS et al., 2002). Assim, ao mesmo tempo em que a globalização produz verticalidades, que são características do meio técnico-científico-informacional, o qual se organiza por meio de objetos esparsos distribuídos globalmente, ela também produz as horizontalidades, que remetem a objetos contíguos, ou seja, se dão no espaço local (SANTOS e SILVEIRA, 2001).

De tal modo, a discussão sobre as dinâmicas espaciais contemporâneas exige a consideração de uma dialética entre o tempo e o espaço, valorizando não somente as formas, mas principamente, as processualidades que se dão de modo desigual, reverberando a divisão do trabalho. Dito de outra forma, a região permanece como um conceito de grande importância para se entender o mundo atual porque os impactos da globalização se dão com intensidades distintas nos lugares.

Com base nessa compreensão, aqui defendemos que na globalização neoliberal a região muda, porém, não deixa de existir. As abordagens tecidas nos paradigmas anteriores da Geografia, que mesmo sob bases teórico-metodológicas diferenciadas, majoritariamente a entendiam quase que como sinônimo de um espaço lento, já não dão conta de explicar o modo como se organiza a sociedade, nem mesmo como ela se apropria da natureza por meio do trabalho. A região precisa ser entendida parte de uma

\begin{tabular}{llllll}
\hline Caminhos de Geografia & Uberlândia - MG & v. 19, n. 68 & Dez/2018 & p. 372-388 & Página 375
\end{tabular}


espacialidade dinâmica e processual em constante articulação com o tempo. Ela é consequência dos diferentes ritmos da expansão espacial capitalista, sendo resultado da relação que se estabelece entre o modo de produção dominante, a igualização e a diferenciação.

Por isso, os próprios processos de regionalização não podem partir somente do espaço herdado, devendo também levar em consideração as estratégias de dominação que estão por trás da construção regional (RIBEIRO, 2004). Em outros termos, muito além de abordar as regiões considerando o clima, o relevo, a vegetação e outros, faz-se relevante destacar os aspectos relacionais dos sujeitos e grupos como parte da compreensão de que o espaço é produzido socialmente.

É com base nessa compreensão que na sequência fazemos uma discussão sobre a soberania alimentar como exemplo de articulação que enfatiza a importância da região para a interpretação da atualidade.

\section{A ESCALA REGIONAL NA PROPOSIÇÃO DA SOBERANIA ALIMENTAR}

Atualmente, a concepção clássica de soberania, baseada nas relações internas e externas ao EstadoNação, tem sido desafiada por novas dinâmicas que enfatizam a diversidade das relações de poder. Não à toa, autores como Conversi (2016), chegam a defender a noção de "soberania líquida" para explicar o mundo contemporâneo, haja vista que o capitalismo se apresenta sob a máscara do neoliberalismo e do projeto de globalização. Sob esse prisma, emergem novas formas de soberania, rementendo a dinâmicas escalares múltiplas e complexas (FOUCAULT, 2008; RAFFESTIN, 1993). Como exemplo, aqui debatemos a soberania alimentar (MCMICHAEL, 2014; PATEL, 2009; SCHIAVONI, 2009). Essa proposta não se acenta na concepção clássica de soberania, onde as relações de poder são construídas "de cima para baixo", pois possui como premissa oportunizar um modelo de desenvolvimento que esteja alicerçado na contribuição dos camponeses e indígenas ao mesmo tempo em que visa garantir alimentos frescos e saudáveis à população residente no campo e na cidade. Ou seja, a soberania alimentar se refere a um formato de soberania construído de "baixo para cima".

A soberania alimentar faz parte de um novo contexto geopolítico em que além dos Estados-Nação, outros sujeitos e instituições também ganham destaque nas disputas pelo(s) poder(es), a exemplo das grandes empresas (CLAPP e FUCHS, 2009; MONTEIRO e CANNON, 2012) e dos movimentos sociais (HOLT GIMÉNEZ e SHATTUCK, 2011; ROUTLEDGE, 1996). A origem dessa proposta remonta ao ano de 1996, quando o conceito de segurança alimentar ganhava grande atenção por parte de governos e instituições multilaterais, especialmente a Organização das Nações Unidas para a Agricultura e Alimentação (FAO) (MURPHY, 2014; SHAW, 2007; SIMON, 2012). Com a segurança alimentar visava-se garantir às pessoas, em sua universalidade, alimentos com qualidade e frequência, contudo, não existia uma preocupação com o modelo de desenvolvimento do campo que iria fazer com que isso acontecesse (WITTMAN, 2011). Em outros termos, poderia ocorrer a segurança alimentar num contexto de hegemonia do agronegócio, mesmo sendo ele o responsável pela saída de milhões de pessoas do campo (FAO, 2006) e por uma substantiva piora na qualidade da comida da população mundial dado o excessivo uso de insumos químicos (BOMBARDI, 2012; FERNANDES, 2004). Visando ir além disso, a soberania alimentar trouxe como preocupação central a busca por modificações estruturais no campo, criando uma alternativa ao modelo de desenvolvimento do agronegócio (ANDRÉE et al., 2014; DESMARAIS, 2006; PATEL, 2012).

A soberania alimentar apareceu como parte de um dos primeiros esforços de inserção da coalizão internacional de movimentos La Via Campesina - fundada em 1993 - no debate sobre os sistemas agroalimentares. De modo mais específico, o marco da incorporação da soberania alimentar pela La Via Campesina é a realização de sua II Conferência Internacional, no ano de 1996, em Tlaxcala, no México. Esse evento deu origem ao documento The right to produce and access to land (O direito de produzir e de acessar a terra), onde defende-se que a segurança alimentar não é suficiente para a eliminação da fome e da pobreza no campo e na cidade. Além disso, nesse documento também é feita uma defesa ao modo de viver e produzir dos camponeses e indígenas, considerando-os como de fundamental importância para promoção de um modelo de desenvolvimento dotado de maior sustentabilidade quando comparado ao capitalista.

Nós, a La Via Campesina, um movimento em desenvolvimento de trabalhadores rurais, camponeses, pequenos proprietários rurais e organizações dos povos indígenas de todas as regiões do mundo, sabemos que a segurança alimentar não pode ser alcançada sem levar totalmente em conta aqueles que produzem os alimentos. Qualquer discussão que ignora

$\begin{array}{llllll}\text { Caminhos de Geografia } & \text { Uberlândia - MG } & \text { v. 19, n. } 68 & \text { Dez/2018 } & \text { p. 372-388 } & \text { Página } 376\end{array}$


nossa contribuição não conseguirá erradicar a pobreza e a fome (LA VIA CAMPESINA, 1996, não paginado, tradução nossa).

Constata-se que a La Via Campesina compreende que a segurança alimentar não pode ser alcançada se não for levada em consideração uma efetiva participação dos pequenos produtores, especialmente os camponeses e indígenas, nos sistemas agroalimentares. Em outros termos, o foco da discussão não pode se dar apenas no acesso ao alimento, mas também nos processos produtivos, de modo que uma das principais preocupações deve ser a criação de condições para que os pequenos agricultores permaneçam na terra, o que evidentemente exige repensar a opção do modelo de livre-mercado no campo. Isso reforça a tese de Mazoyer e Houdart (2006), de que para a existência de sistemas agroalimentares democráticos e efetivos se faz necessário pensar não apenas no barateamento do preço dos alimentos, mas também na criação de oportunidades que viabilizem os pequenos produtores. Nesse contexto, a soberania alimentar foi definida primeiramente como sendo:

[...] o direito de cada nação de manter e desenvolver a sua própria capacidade de produzir os seus alimentos básicos, respeitando a diversidade cultural e produtiva. Nós temos o direito de produzir nosso próprio alimento em nosso próprio território. A soberania alimentar é uma condição prévia para uma verdadeira segurança alimentar (LA VIA CAMPESINA, 1996, não paginado, tradução nossa, grifos nossos).

Nessa primeira definição trazida pela La Via Campesina, entende-se que a soberania alimentar deve ocorrer na escala da nação, de modo que sejam respeitadas sua diversidade cultural e produtiva. Sobre isso, vale lembrar que nação não é sinônimo de Estado-Nação, pois a base territorial é a condição para a existência do segundo, ao passo que muitos exemplos do primeiro são desprovidos desse triunfo/trunfo, como é o caso dos curdos (distribuídos por países como Armênia, Azerbaijão, Irã, Iraque, Síria e Turquia) e dos ciganos (distribuídos por países como Brasil, Estados Unidos, Portugal, Espanha, Romênia, França, Bulgária e Hungria). Assim, nessa primeira definição, ao pontuar a escala da nação e não a do Estado-Nação para a ocorrência da soberania alimentar, a La Via Campesina dá ênfase a uma das principais dinâmicas da complexidade do conceito de região na atualidade que é a ocorrência de regionalismos que não se dão numa base territorial específica, mas de modo disperso e articulado. Isso torna pertinente a contribuição de Allen, Massey e Cochrane (1998), os quais entendem que contemporaneamente, a leitura tradicional da Geografia, que entendia a região mais pela perspectiva zonal, perde importância, pois as regiões são formadas, principalmente, por porosidades. Indo além disso, Haesbaert (1999), propõe pensar esse conceito também por meio das articulações em rede, de modo que a dinâmicas areais e fluxas se relacionam de modo complexo no espaço.

Pensar a soberania alimentar na escala das nações é um primeiro passo dado pela La Via Campesina para trabalhar com a complexidade espacial que envolve o conceito de região na atualidade. Como constatamos nos trabalhos de campo, o Canadá pode ser tomado como exemplo disso, pois apesar de se organizar como uma federação, nações indígenas têm incorporado a bandeira da soberania alimentar, principalmente ao trabalhar com a necessidade de se considerar a dimensão cultural do alimento (RUDOLPH e McLACHLAN, 2013). Autores como Kepkiewicz (2017) e Desmarais e Wittman (2014) chegam até mesmo a ver na incoporação da soberania alimentar por nações indígenas uma proposta anticolonial.

Essa compreensão da ocorrência da soberania alimentar na escala da nação foi hegemônica até o ano de 2007, quando ocorreu o Foro Mundial pela Soberania Alimentar, no vilarejo de Nyéleni, no Mali, o qual teve a participação de 500 representantes de organizações camponesas, vindos de 80 países. Como resultado das discussões ocorridas nesse evento, foi produzido o documento Declaration of Nyéléni (Declaração de Nyéléni), onde a soberania alimentar foi definida como:

[...] um direito dos povos a alimentos nutritivos e culturalmente adequados, acessíveis, produzidos de forma sustentável e ecológica, e seu direito de decidir seu próprio sistema alimentício e produtivo. Isto coloca aqueles que produzem, distribuem e consomem alimentos no coração dos sistemas e políticas alimentares, por cima das exigências dos mercados e das empresas.

\begin{tabular}{llllll}
\hline Caminhos de Geografia & Uberlândia - MG & v. 19, n. 68 & Dez/2018 & p. 372-388 & Página 377
\end{tabular}


Defendendo os interesses de, e inclusive, às futuras gerações (FORUM FOR FOOD SOVEREIGNTY, 2007, não paginado, tradução nossa, grifo nosso).

Assim, foi-se pontuado o que é, quem realiza, porquê, como, onde, quando e o que aconteça na proposta de soberania alimentar (ALONSO-FRADEJAS et al., 2015). Na Declaração de Nyeleny constam ainda os seis pilares para a efetivação da soberania alimentar: i) a comida deve ser destinada para as pessoas; ii) é preciso construir conhecimentos e habilidades locais; iii) o trabalho agrícola deve ser efetivado com respeito aos recursos naturais; iv) os valores dos provedores de alimentos precisam ser preservados; v) é fundamental o privilégio aos sistemas alimentares locais e; vi) os povos locais devem ter o controle sobre os seus sistemas alimentares (FORUM FOR FOOD SOVEREIGNTY, 2007). Posteriormente, no ano de 2011, com base na contribuição de indígenas canadenses, seria acrescentado o sétimo pilar, que é a dimensão sagrada do alimento (TRAUGER, 2015).

Todavia, para efeito da discussão aqui realizada, vale destacar que na Declaração de Nyéleni aparece uma nova narrativa escalar sobre a soberania alimentar. Já não se entende mais que ela deve ocorrer na escala da nação e sim como uma construção de cada povo, o que valoriza o local, o comunitário e principalmente, o regional. Em outros termos, "construiu-se uma ideia de soberania societária, comunitária ou, como dizem alguns dirigentes, cidadã" (VIEIRA, 2008, p.7). Isso não quer dizer que as outras escalas são desprezadas, pelo contrário, entende-se que a incorporação da soberania alimentar deve se dar por meio da articulação entre diferentes níveis escalares (COCA, 2016a).

Com essa definição, evidenciou-se de modo mais enfático a relação entre a soberania alimentar e a região. Num contexto em que, cada vez mais, os sistemas agroalimentares são organizados globalmente por meio da ação das grandes corporações como parte da globalização neoliberal (McMICHAEL, 2003), a proposta de soberania alimentar pontua a construção de alternativa de baixo para cima (TRAUGER, 2017). Isso envolve a construção de canais como mercados locais (WITTMAN, 2011), redes de comércio solidário (RENTING et al., 2003), o acesso dos pequenos produtores aos mercados institucionais (WITTMAN, 2015) entre outros. Soberania alimentar significa que em cada região, os povos que ali vivem têm o direito de escolher o que irão comer, valorizando sua cultura e indo além da padronização da dieta alimentar que tem sido efetivada em escala mundial, através da introdução massiva dos alimentos processados pelas grandes corporações. No dizer de Stédile e Carvalho (2011, não paginado, grifos dos autores):

[...] soberania alimentar significa que cada comunidade, cada município, cada região, cada povo, tem o direito e o dever de produzir seus próprios alimentos. Por mais dificuldades naturais que houver, em qualquer parte do nosso planeta, as pessoas podem sobreviver e se reproduzir dignamente. Já existe conhecimento cientifico acumulado, para enfrentar as dificuldades naturais e garantir a produção de bens suficientes para sua reprodução social.

Essa concepção aparece, por exemplo, nas articulações contemporâneas dos movimentos camponeses vinculados à La Via Campesina que atuam no Brasil. Uma análise das pautas de luta do Movimento dos Trabalhadores Rurais Sem-Terra (MST), por exemplo, indica que até o final da década de 1990, a preocupação central era a implementação da reforma agrária, visando a desconcentração fundiária (FERNANDES, 2000). Contudo, com o século XXI, novos temas têm sido incorporados, a exemplo da agroecologia e da soberania alimentar como constatamos nos trabalhos de campo nos territórios da cidadania do Cantuquiriguaçu e do Pontal do Paranapanema. Isso se enquadra numa perspectiva de que o acesso à terra, por meio das políticas de reforma agrária, deve ser acompanhado da criação de medidas que possibilitem a permanência na terra, de modo que os beneficiários pelas políticas de reforma agrária possam contribuir de modo direto com 0 desenvolvimento regional por meio da oferta de alimentos frescos, saudáveis e que respondam à cultura do povo que ali vive (FERNANDES et al., 2017).

Vemos assim, que a soberania alimentar aparece como um exemplo de que por mais que a globalização se caracterize por fatores como a aceleração dos fluxos e a consequente sensação de diminuição das distâncias, na verdade, não ocorre a homogeneização do espaço. Isso porque, ao mesmo tempo em que produz a igualização, ela também gera a diferenciação. Como resultado disso,

$\begin{array}{lllllll}\text { Caminhos de Geografia } & \text { Uberlândia - MG } & \text { v. 19, n. } 68 & \text { Dez/2018 } & \text { p. 372-388 } & \text { Página } 378\end{array}$


a soberania alimentar emerge como um processo de resistência local/regional contra os efeitos perversos da globalização neoliberal. No dizer de McMichael (2014, p.352, tradução nossa):

\begin{abstract}
[...] a soberania alimentar não rejeita o "global" em detrimento do "local", ao invés disso, ela redefine o global em termos adequados às condições democráticas de produção e distribuição de alimentos. Essa coalização camponesa [La Via Campesina] enfatiza duas premissas centrais: primeiro, que as tensões internacionais envolvendo as políticas de alimentos, ultimamente derivam do conflito entre os modos de produção e o desenvolvimento rural e; segundo, que a luta é global, porém, descentralizada em conteúdo e liderança.
\end{abstract}

De tal maneira, a resistência estabelecida na escala local por meio da proposição da soberania alimentar, aparece como um exemplo de que por mais que seja hegemônica, a globalização não gera a homogeneização do espaço. Como pode-se perceber em trabalhos como os de Fraser et al. (2016), Andrée et al. (2014) e Wekerle (2004), apesar de não existir um consenso sobre o que é a escala local, o mais comum é que ela seja lida como uma referência ao regional. O que se define como "comida local" pode variar de uma localidade para outra. Na região da Colúmbia Britânica, no Canadá, por exemplo, devido à baixa produtividade da terra, parcela significativa das frutas e verduras consumidas por sua população vêm do estado da Califórnia, nos Estados Unidos (MANSFIELD, 2014). Nesse caso, como constatamos nos trabalhos de campo, é comum que ativistas alimentares entendam o local por meio de uma articulação transnacional. Isso pode ser tomado como um exemplo de que na atualidade, a definição das regiões (ou processo de regionalização) deve remeter não a um espaço lento, mas à dialética entre os fixos e os fluxos, o todo e as partes e o material e o imaterial. Isso reforça a tese de que a leitura contemporânea das regiões e dos processos a elas relacionados deve partir da consideração de que o espaço é formado por relações complexas e dinâmicas em constante articulação com o tempo.

\title{
A SOBERANIA ALIMENTAR E OS NOVOS SIGNIFICADOS DA REGIÃO NO BRASIL E NO CANADÁ
}

A ideia defendida nesse trabalho de que ações embasadas na soberania alimentar podem ser tomadas como exemplos de uma resingificação das regiões no contexto de globalização neoliberal foi empiricamente reforçada com a realização de trabalhos de campo no Brasil e no Canadá, onde abordamos diferentes estratégias que visam modificar estruturalmente os sistemas alimentares. $\mathrm{Na}$ sequência destacamos algumas observações sobre esses exemplos como forma de ampliar a discussão aqui proposta.

No caso do Brasil, foram pesquisados dois territórios da cidadania: o Cantuquiriguaçu, que é composto por 20 municípios do Centro-Sul do estado do Paraná e o Pontal do Paranapanema, formado por 32 municípios do Oeste do estado de São Paulo. Vale ressaltar que, a definição dos territórios da cidadania é um processo de regionalização efetivado pelo Estado, haja vista que nesses casos, o Governo Federal elenca conjuntos de municípios com precários indicadores socioeconômicos para que neles sejam efetivadas políticas públicas divididas em três eixos: direitos sociais, geração de renda e infraestrutura (COCA, 2015; MDA, 2012). Assim, a definição de território utilizada nessa estratégia de articulação de políticas públicas é apenas operacional, de modo que para a Geografia, essa acepção remete de modo mais enfático ao conceito de região (COCA, 2016a).

Um dos principais componentes dos territórios da cidadania é a presença de conflitos pela posse da terra e assentamentos rurais. Isso faz com que nessas regiões, camponeses articulados por movimentos sociais estejam entre alguns dos principais agentes produtores do espaço. De tal modo, tanto no Cantuquiriguaçu quanto no Pontal do Paranapanema são constatados movimentos camponeses vinculados à La Via Campesina, que como vimos, é a principal propositora da soberania alimentar. Em razão disso, uma série de ações efetivadas por esses movimentos camponeses, seja através de políticas públicas ou não, podem ser tomadas como exemplos da resifignação da região por meio da soberania alimentar, indo além da perspectiva de homogeneização do espaço gerada pela globalização.

No Cantuquiriguaçu, por exemplo, movimentos camponeses como o MST e o Movimento dos Pequenos Agricultures (MPA) - ambos integrantes da La Via Campesina - têm trabalhado com a

$\begin{array}{llllll}\text { Caminhos de Geografia } & \text { Uberlândia - MG } & \text { v. 19, n. } 68 & \text { Dez/2018 } & \text { p. 372-388 } & \text { Página } 379\end{array}$


ideia de que a soberania alimentar deve ser construída em escala regional por meio de mudanças que não remetam apenas aos aspectos de produção agrícola, mas que também incorporem outras dimensões da realidade. Isso ficou explícito quando, na primeira década de século XXI, houve uma articulação entre os movimentos camponeses da região e prefeituras com a presença do Partido dos Trabalhadores (PT) para a condução do Conselho de Desenvolvimento do Território Cantuquiriguaçu (CONDETEC), responsável por gerir o Programa Territórios da Cidadania nesse conjunto de municípios. Isso redundou em importantes conquistas que, de modo direto ou indireto, visavam fortalecer a soberania alimentar na escala regional. São exemplos: i) investimentos na cadeia leiteira como forma de gerar renda para a populção camponesa; ii) a melhoria da infrestrutura de casas do trabalhador rural, por meio construção de alojamentos e salas de aula nas unidades de Porto Barreiro, Rio Bonito do Iguaçu, Três Barras do Paraná, Pinhão, Guaraniaçu e Nova Laranjeiras; iii) o incentivo à Educação do Campo, especialmente por meio do Projeto Saberes da Terra, presente em 11 municípios, tendo por objetivo contribuir com a escolarização e qualificação profissional dos jovens camponeses e; iv) a implantação de um dos campi da Universidade Federal da Fronteira Sul (UFFS), no assentamento 08 de Junho, em Laranjeiras do Sul (Figura 1), o qual foi conquistado por meio da luta pela terra travada pelo MST. Nesse centro universitário são ofertados os seguintes cursos: Agronomia, Ciências Econômicas (com ênfase em Economia Solidária), Engenharia de Alimentos, Engenharia de Aquicultura, Interdisciplinar em Educação do Campo, Interdisciplinar em Educação do Campo: Ciências Humanas e Sociais. Todos eles possuem como foco transversal a Agroecologia, que é um dos pilares para a implementação da soberania alimentar (ALTIERI, 2009).

Figura 1: Campus da Universidade Federal da Fronteira Sul (UFFS), no assentamento 08 de Junho, em Laranjeiras do Sul - PR

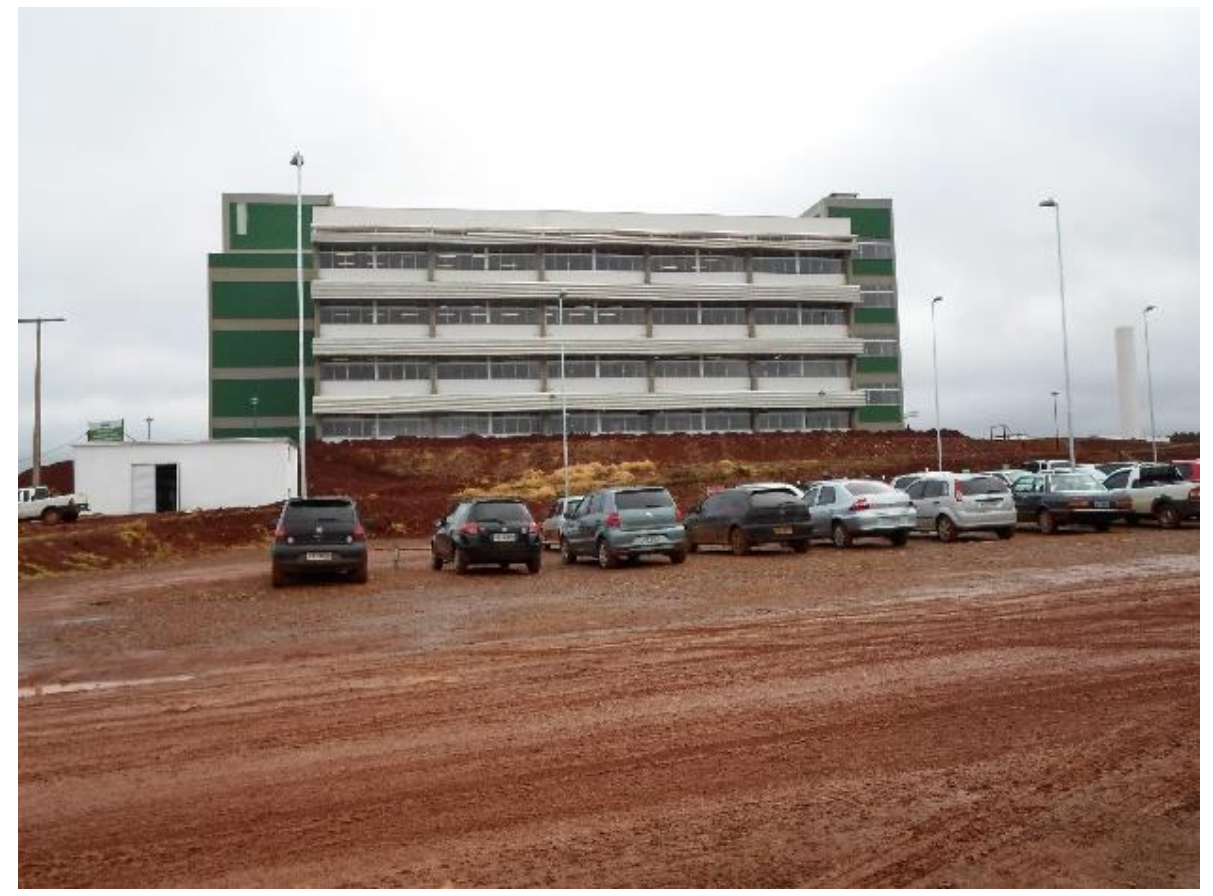

Foto: Autor, 2013.

Sobre essa leitura dos movimentos camponeses do Cantuquiriguaçu de disputar a escala regional por meio do Programa Territórios da Cidadania é ilustrativa a seguinte colocação:

A máquina do estado não está pensada territorialmente, ela está pensada em territórios municipais. Então, quando você vai discutir uma estratégia regional, você enfrenta um mundo de dificuldades; os movimentos têm menos dificuldades, porque o movimento tem visão regional, não fica 
preso à fronteira do município e tal, mas você vai discutir com o estado, o estado se materializa no nacional, na esfera estadual e na esfera municipal, então se você tratar com um prefeito é uma situação, se tratar com outro é outra. Você pensar um projeto que abrange dois, três municípios, exige aí um mecanismo em manejo e negociações de outro vulto. (V. S. - Membro do MPA e Ex-participante do Núcleo Diretor do CONDETEC - 06/2014).

Nesse depoimento fica evidente a ideia dos movimentos camponeses vinculados à La Via Campesina de disputarem a escala regional como forma de contribuir para a implementação de um modelo de desenvolvimento que privilegie outras relações de produção, além das que são efetivadas pelo agronegócio, sendo que a soberania alimentar é parte estrutural dessa proposição. Assim, percebe-se de modo enfático que a região aparece como espaço de luta, de tal modo que, no contexto de hegemonia do regime agroalimentar corporativo que está estruturado globalmente, a escala regional é vista como estratégica para que os movimentos camponeses defendam seu modo de vida e produção. Evidentemente, isso não nega o fato de que eles também estão inseridos em outras escalas, como é o caso da global, por meio da La Via Campesina, porém, percebe-se que a região é ressignificada enquanto uma escala estratégia para o exercício do poder.

O Pontal do Paranapanema também contém elementos de referência para essa discussão, especialmente no que tange às relações entre as comunidades camponesas e o Estado com a intenção de fortalecer mecanismos de produção e consumo de alimentos na escala regional. Pode-se citar do Programa de Aquisição de Alimentos (PAA), o qual, vale ressaltar, é a resposta a uma demanda apresentada principalmente por movimentos camponeses vinculados à La Via Campesina visando garantir parcelas do mercado institucional para a agricultura de base familiar (PORTO et al., 2014). O PAA possui dois objetivos centrais: i) a compra de alimentos produzidos em unidades de produção camponesas sem a ocorrência de licitação e; ii) a doação de parte desses produtos para instituições que atendem pessoas em situação de vulnerabilidade social. Diversos trabalhos têm pontuado a contribuição dessa política pública para a implementação da soberania alimentar na escala regional, a exemplo dos de Wittman (2015), Coca (2016c) e Vinha e Schiavinatto (2015).

Um dos principais elementos do PAA que podem ser tomados como referência para relação entre a soberania alimentar e a ressignificação do espaço regional é a relevância dada à Questão de Gênero. A importância disso reside no fato de que, atualmente, devido ao caráter patriarcal que predomina na maior parte das comunidades rurais, o trabalho da mulher é invisibilizado (LEVIEN, 2017). Ao mesmo tempo, constata-se que em escala global existe um processo de feminização do campo (De SCHUTTER, 2013). Recohecendo tal contexto, pode-se afirmar que a superação do regime agroalimentar corporativo por meio da soberania alimentar deve levar em consideração o protagonismo feminino.

No ano de 2012, dentre as 74 entidades proponentes do PAA no Pontal do Paranapanema, 08 eram formadas por mulheres, sendo elas: a Associação dos Produtores Rurais do Assentamento Maturi e Reassentamento do Projeto Lagoa São Paulo, de Caiuá; a Organização de Mulheres do Assentamento Tucano (OMAT), de Euclides da Cunha Paulista; a Associação dos Produtores Rurais do Bairro Areia Branca, de Marabá Paulista; a Associação das Mulheres Assentadas da Região do Pontal do Paranapanema, a Associação Feminina do Município de Mirante do Paranapanema e a Associação Pecuária e Agrícola do Município de Mirante do Paranapanema (APAMP), todas de Mirante do Paranapanema, além da Organização das Mulheres Unidas do Setor II da Gleba XV de Novembro (OMUS), de Rosana. Todas essas entidades proponentes do PAA no Pontal do Paranapanema que são formadas por mulheres têm origem nos assentamentos rurais. Isso denota que como parte do aprendizado de luta pela terra e de luta na terra, o componente gênero se torna uma referência. No ano de 2012, no que se refere à modalidade Compra com Doação Simultânea do PAA, essas entidades proponentes formadas por mulheres foram responsáveis pela comercialização de 70 tipos de produtos no Pontal do Paranapanema, sendo que dentre eles, além de frutas, legumes e verduras in natura, também constavam beneficiados (farinha de mandioca, polvilho, bolacha, doce de leite, polpa de acerola, queijo e polvilho) e de origem animal (ovos de galinha, tilápia e frango vivo). Ou seja, percebe-se que as mulheres têm exercido um papel de grande importância para que sejam criadas

\begin{tabular}{llllll}
\hline Caminhos de Geografia & Uberlândia - MG & v. 19, n. 68 & Dez/2018 & p. 372-388 & Página 381
\end{tabular}


alternativas para a agregação de valor aos produtos, não se limitando aos trabalhos realizados nas hortas localizadas nas unidades de produção familiar/camponesas.

Portanto, percebe-se que no Pontal do Paranapanema, as entidades proponentes formadas por mulheres agricultoras familiares/camponesas têm exercido um relevante papel na implementação do PAA. Isso faz com que elas reafirmem sua contribuição para o sistema alimentar em âmbito regional. $\mathrm{Na}$ escala da unidade de produção familiar/camponesa, percebe-se que o PAA tem reforçado o papel das mulheres no cuidado das hortas, o que denota que além de contribuírem com os afazeres domésticos e cuidarem dos filhos, elas também têm sido fundamentais para o desempenho produtivo. "Hoje, para você fazer um projeto para a CONAB, você deve ter no mínimo $40 \%$ de mulheres. Quem trabalha mais no sítio são as mulheres, na horta, os homens não trabalham, eles vão tirar leite e fazer outras coisas, mas isso não, a parte da horta é a mulher" (E. F. - Proponente do PAA em Sandovalinia - SP - 26/07/2014). De tal maneira, o trabalho feminino tem sido importante para que o PAA contribua com a diversificação produtiva nas unidades de produção familiar/camponesas do Pontal do Paranapanema. Isso reforça leitura realizada por Desmarais (2002), que entende que um dos meios pelos quais as mulheres podem contribuir para a construção da soberania alimentar é através do incentivo à biodiversidade nas comunidades rurais.

Nesses termos, constata-se que num contexto de ressignificação da região como parte das contradições da globalização neoliberal, a dinâmica de gênero adquire grande importância na discussão da diferenciação espacial. Ao valorizar o trabalho feminino, o PAA fortalece o papel das mulheres como provedoras de alimento na escala regional, indo além da masculinização característica do regime agroalimentar corporativo. Dito de outro modo, a Questão de Gênero aparece como um dos componentes do Novo Regionalismo.

Sobre o Canadá, dentre as principais ações embasadas nos princípios da soberania alimentar com impactos na ressignificação da região, destacam-se os diversos movimentos e organizações que possuem como objetivo diminuir a distância que o alimento percorre da unidade de produção até a mesa do consumidor.

$\mathrm{Na}$ América do Norte tem sido crescente a formação de grupos de consumidores que utilizam o slogan buy local (compre local). Eles visam incentivar os consumidores a privilegiarem produtos alimentares que são cultivados na escala local/regional. Isso tem sido nomeado por autores como De Schutter (2015) e McMichael (2014) como exemplos da "segunda geração" da soberania alimentar, onde além das relações de produção também passam a ser tratadas como de suma importância para a modificação estrutural dos sistemas agroalimentares as relações de consumo.

Ressalta-se que em média, as refeições realizadas pelos moradores da América do Norte viajam $2.400 \mathrm{~km}$ até chegar à mesa das famílias consumidoras (GET LOCAL BC, 2015). Visando modificar essa situação e tendo por lema a frase think global, buy local (pense global, compre local) esses grupos de consumidores têm sido responsáveis pelo questionamento sobre o "lugar" do alimento nos países considerados ricos (FEAGAN, 2007). Isso indica que o nítido intuito de disputar as escalas percorridas pelo alimento até o seu consumo. De tal modo, a comercialização e o consumo dos alimentos são influenciados por fatores como a proximidade do lugar em que eles são cultivados, os impactos ambientais causados na sua produção e outros. Em outros termos, o objetivo central dessas ações é aproximar os produtores dos consumidores, modificando a espacialidade do abastecimento de alimentos (SONNINO, 2010).

Nesse caso, ao também considerar a importância da ocorrência de modificações nos sistemas agroalimentares pela via do consumo para a implementação da soberania alimentar, percebe-se uma nítida afirmação do regional em relação ao global. Em outros termos, compreende-se que "'[...] o dinheiro local e dinheiro do contribuinte local devem apoiar também as economias locais. [...] (S. L. Coordenadora de Comunicação e Extensão do Centro de Sistemas Alimentares Sustentáveis da University of British Columbia - UBC Farm - Vancouver - 16/06/2015). São exemplos de tais ações mercados de produtores orgânicos regionais (Figura 2) e hortas urbanas (Figura 3).

De tal modo, no caso do Canadá, principalmente por meio das relações de consumo, a "segunda geração" da soberania alimentar pode ser tomada como um exemplo da reemergência da região no contexto de globalização neoliberal. Esse exemplo indica que o Novo Regionalismo tem como um de seus componentes a leitura das relações de consumo como dotadas de caráter multidimensional, pois estão relacionadas à resilência dos pequenos produtores que atuam na região no sistema capitalista estruturado globalmente por meio de grandes corporações.

\begin{tabular}{llllll}
\hline Caminhos de Geografia & Uberlândia - MG & v. 19, n. 68 & Dez/2018 & p. 372-388 & Página 382
\end{tabular}


Figura 2 - Mercado de produtores locais da Ontario Street - Vancouver

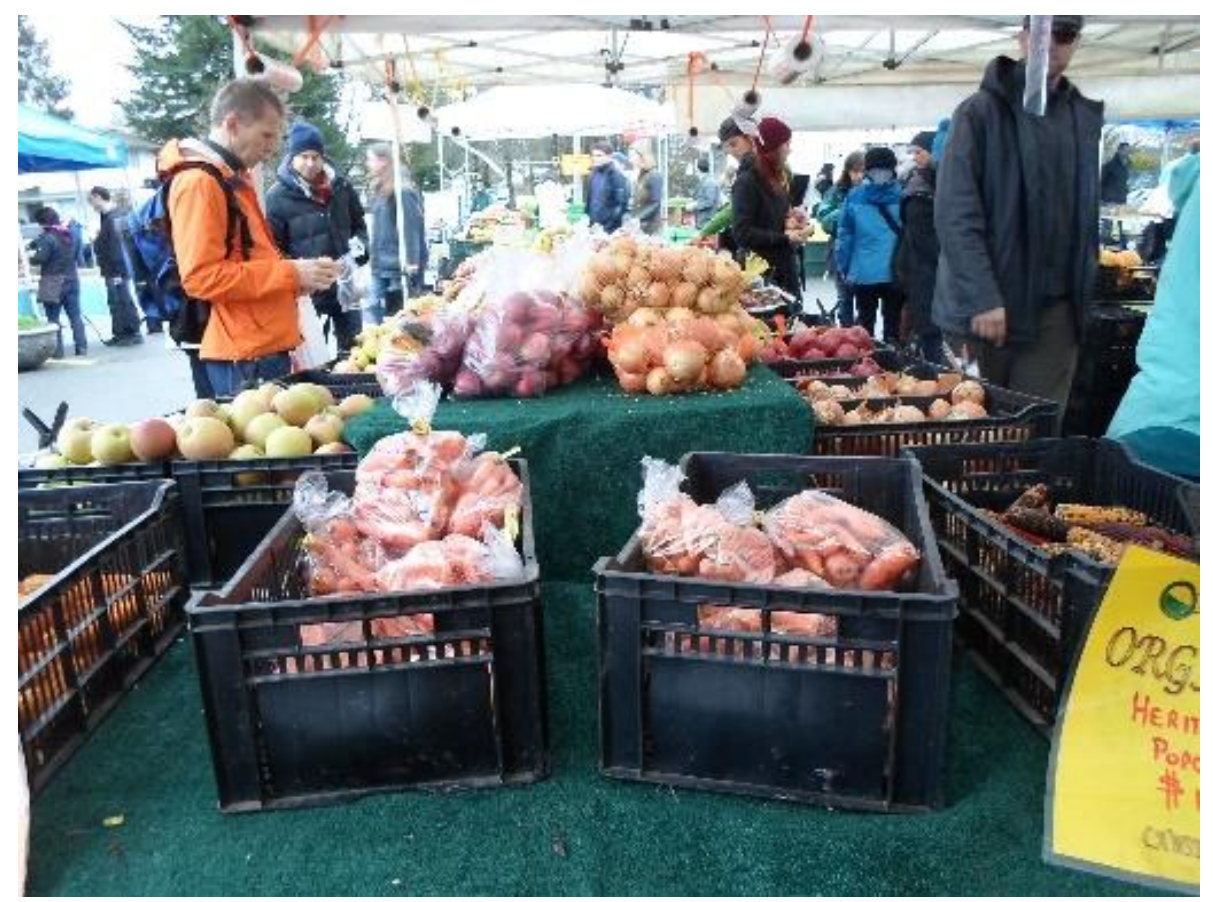

Foto: Autor, 2015.

Figura 3: Argile Urban Garden - West Vancouver

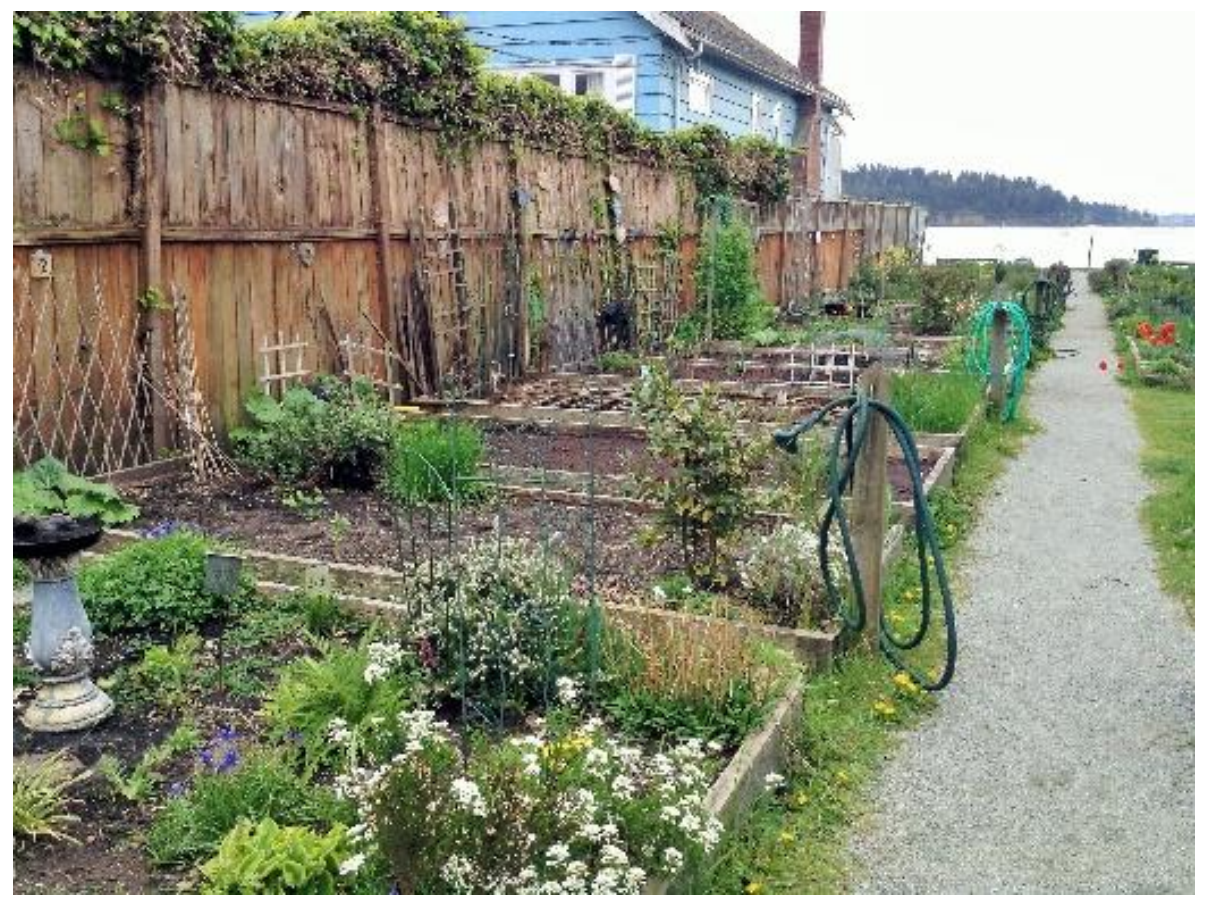

Foto: Autor, 2015.

\section{CONSIDERAÇÕES FINAIS}

Esse trabalho trouxe uma discussão sobre a leitura contemporânea do conceito de região pela Geografia por meio da proposta de soberania alimentar, a qual tem sido pontuada pela articulação 
global de movimentos e organizações camponesas La Via Campesina como uma alternativa ao crescente controle exercido pelas grandes corporações sobre os sistemas agroalimentares.

Primeiramente, foi feito um resgate da leitura do conceito de região pelos paradigmas da Geografia. Demonstrou-se como até meados do século $\mathrm{XX}$, predominaram as interpretações da região como sinônimo de um espaço herdado, remetendo a um tempo lento, ou seja, não era dada ênfase à dinamicidade do espaço. Contudo, com a emergência das abordagens críticas que caracterizam a Geografia atual, existe a possibilidade de ler o espaço para além de sua fetichização e com isso, trabalha-se a região de modo mais complexo, considerando suas porosidades e a relação direta que elas estabelecem com as redes.

Concordando com essas acepções, fizemos a defesa de que a globalização não gera uma completa homogeneização do espaço. Isso porque, apesar de ela ser responsável por uma considerável aceleração dos fluxos, levando muitos a falarem de um "mundo sem fronteiras", na verdade, ela é responssável tanto pela igualização como pela diferenciação. A globalização não atinge a todos os lugares com a mesma intensidade, pois ela reflete os contraditórios processos da divisão do trabalho. É nesse contexto que aqui defendemos a pertinência atual do conceito de região. Ela é produzida como parte do desenvolvimento desigual do capitalismo, o qual possui consideráveis repercussões espaciais.

Desse modo, tomamos o exemplo da construção da soberania alimentar como um processo "de baixo para cima", afim de destacar a permanência atual do conceito de região. Demonstramos que num primeiro momento, a La Via Campesina defendeu a ocorrência da soberania alimentar na escala da nação para depois vinculá-la a uma dinâmica que envolve os povos (comunidades). Com exemplos do Brasil e do Canadá demonstramos que isso se insere numa perspectiva que visa pensar o desenvolvimento das regiões para além da dinâmica que tem sido estabelecida pelo capitalismo, considerando como elementos fundamentais não apenas o consumo de alimentos, como defendido pela segurança alimentar, mas também, a produção dos mesmos.

\section{REFERÊNCIAS}

ALLEN, J.; MASSEY, D.; COCHRANE, A. Rethinking the region. Londres: Psychology Press, 1998.

ALONSO-FRADEJAS, A.; HOLT-GIMÉNEZ, E.; ROBBINS, M. J.; BORRAS JR, S.; HOLMES, T. Food sovereignty: convergence and contradictions, conditions and challenges. Third World Quarterly, Waterloo, v. 36, n. 3, p. 431-448, 2015. https://doi.org/10.1080/01436597.2015.1023567

ALTIERI, M. Agroecoloy, small farms and food sovereignty. Monthly Review, New York, p. 102-113, 2009.

ALVES, E. Descentralização e políticas públicas no Brasil: da crise do Estado ao neoliberalismo dos anos 90. In: V Encontro de Economistas de Língua Portuguesa, 2003, Recife. Anais do Encontro de Economistas de Língua Portugues. Recife: Universidade Federal de Pernambuco, 2003.

ANDRÉE, P.; AYRES, J.; BOSIA, M. J.; MASSICOTE, M. J. Globalization and food sovereignty: global and local change in the new politics of food. Toronto: University of Toronto Press, 2014.

https://doi.org/10.3138/9781442696860

ARRETCHE, M. Mitos da descentralização: mais democracia e eficiência nas políticas públicas? Revista Brasileira de Ciências Sociais, São Paulo,n. 31, p. 44-66, 1996.

BENKO, G. A recomposição dos espaços. Interações, Campo Grandev. 1, n. 2, p. 7-12, 2001.

BENKO, G.; LIPIETZ, A. As regiões ganhadoras - distritos e redes: os novos paradigmas da geografia econômica. Lisboa: Celta, 1994.

BOMBARDI, L. M. Agrotóxicos e agronegócio: arcaico e moderno se fundem no campo brasileiro. In: MERLINO, T.; MENDONÇA, M. L. (Orgs.). Direitos humanos no Brasil 2012: relatório da Rede Social de Justiça e Direitos Humanos. São Paulo: Rede Social de Justiça e Direitos Humanos; 2012. p. 75-86.

CARGNIN, A. P. Desafios para o planejamento e o desenvolvimento territorial no estado do rio grande do sul challenges for territorial planning and development in the rio grande do sul state. Geographia Meridionalis, Pelotas, v. 2, n. 2, p. 214-233, 2016. https://doi.org/10.15210/gm.v2i2.9311

CLAPP, J.; FUCHS, D. Corporate power in global agrifood governance.

Cambridge/Massachusetts/Londres: MIT Press, 2009.

https://doi.org/10.7551/mitpress/9780262012751.001.0001

\begin{tabular}{llllll}
\hline Caminhos de Geografia & Uberlândia - MG & v. 19, n. 68 & Dez/2018 & p. 372-388 & Página 384
\end{tabular}


COCA, E. L. F. O desenvolvimento territorial no Paradigma do Capitalismo Agrário (PCA). Revista da ANPEGE, Dourados, v. 10, n. 13, p. 107-130, 2015.

COCA, E. L. F. A soberania alimentar através do Estado e da sociedade civil: o Programa de Aquisição de Alimentos (PAA), no Brasil e a rede Farm to Cafeteria Canada (F2CC), no Canadá. 2016a. Tese (Doutorado em Geografia). Universidade Estadual Paulista (Unesp), Presidente Prudente.

COCA, E. L. F. 20 anos da proposta de soberania alimentar: construindo um regime alimentar alternativo. Revista NERA, Presidente Prudente, n. 19, p. 14-33, 2016b.

COCA, E. L. F. A contribuição do Programa de Aquisição de Alimentos (PAA) para a soberania alimentar no Pontal do Paranapanema. Formação, Presidente Prudente, v. 2, n. 23, p. 57-81, 2016c.

CONVERSI, D. Sovereignty in a changing world: from Westphalia to food sovereignty. Globalizations, Melbourne v. 7731, n. March, p. 1-15, 2016. https://doi.org/10.1080/147477731.2016.1150570

De SCHUTTER, O. The agrarian transition and the "feminization" of agriculture. In: Food sovereignty: a critical dialogue (International Conference): Anais... New Haven: ISS-Agrarian, Food \& Environmental Studies (AFES), Initiatives in Critical Agrarian Studies (ICAS), ransnational Institute (TNI), Institute for Food and Development Policy/Food First, Land Deal Politics Initiative (LDPI), The Journal of Peasant Studies, 2013.

De SCHUTTER, O. Food democracy South and North: from food sovereignty to transition initiatives. Open Democracy, Londres, 2015.

DESMARAIS, A. A. Peasants speak - the Vía Campesina: consolidating an international peasant and farm movement. Journal of Peasant Studies, Hague, v. 29, n. 2, p. 91-124, 2002.

https://doi.org/10.1080/714003943

DESMARAIS, A. A. Peasant resistance to neoliberalism: La Via Campesina and food Sovereignty. Human Geography: a new radical journal, Bolton. n.1. 2006.

DESMARAIS, A. A.; WITTMAN, H. Farmers, foodies and First Nations: getting to food sovereignty in Canada. Journal of Peasant Studies, Hague,v. 41, n. 6, p. 1153-1173, 2014.

https://doi.org/10.1080/03066150.2013.876623

FAO - FOOD AND AGRICULTURE ORGANIZATION OF THE UNITED NATIONS. La inversión agrícola contribuye a contener el éxodo rural2006. Disponível em:

<http://www.fao.org/newsroom/es/news/2006/1000313/index.html>. Acesso em: 11 de nov. de 2015.

FEAGAN, R. The place of food: mapping out the "local" in local food systems. Progress in Human Geography, Manchester, v. 31, n. 1, p. 23-42, 2007. https://doi.org/10.1177/0309132507073527

FERNANDES, B. M. A formação do MST no Brasil: Petrópolis: Vozes, 2000.

FERNANDES, B. M. O novo nome é agribusiness. Presidente Prudente, 2004.

FERNANDES, B. M.; COCA, E. L. F.; VINHA, J. F. S. C.; CLEPS JÚNIOR, J.; DANTAS, J. C.; SOBREIRO FILHO, J. A questão agrária na segunda fase neoliberal no Brasil. In: MEDEIROS, R. M. V.; LINDNER, M. (Orgs.). Dinâmica do espaço agrário: velhos e novos territórios. Porto Alegre: Evangraf, 2017. p. 2015235.

FORUM FOR FOOD SOVEREIGNTY. Declaração de Nyéléni, 2007.

FOUCAULT, M. Microfísica do Poder. Rio de Janeiro: Graal, 2008.

FRASER, E.; LEGWEGOH, A.; KC, K.; CoDYRE, M.; DIAS, G.; HAZEN, S.; JOHNSON, R.; MARTIN, R.; OHBERG, L.; SETHURATNAM, S.; SNEYD, L.; SMITHERS, J.; Van ACKER, R.; VANSTEENKISTE, J.; WITTMAN, H.; YADA, R. Biotechnology or organic? Extensive or intensive? Global or local? A critical review of potential pathways to resolve the global food crisis. Trends in Food Science and Technology, Wageningen, v. 48, p. 78-87, 2016. https://doi.org/10.1016/..tifs.2015.11.006

FREMONT, A. A região, espaço vivido. Coimbra: Edições Almediana, 1980.

GET LOCAL BC. The benefits of eating locally. 2015. Disponível em: <http://www.getlocalbc.org/>. Acesso em: 20 jun. 2018.

GRAMSCI, A. A Questão Meridional. Rio de Janeiro: Paz \& Terra, 1987.

GRIGG, D. Regiões, modelos e classes. Boletim Geográfico, Rio de Janeiro, n. 32, p. 3-46, 1973.

\begin{tabular}{llllll}
\hline Caminhos de Geografia & Uberlândia - MG & v. 19, n. 68 & Dez/2018 & p. 372-388 & Página 385
\end{tabular}


HAESBAERT, R. Região, diversidade territorial e globalização. Geographia, Rio de Janeiro, n. 1, p. 1539, 1999.

HAESBAERT, R. Região: trajetos e perspectivas. Anais... I Jornada de Economia Regional Comparada, Porto Alegre: FEE, 2005.

HAHN, H.; NEURATH, O.; CARNAP, R. A concepção científica do mundo - o Círculo de Viena. Viena, 1929.

HARVEY, D. The condition of postmodernity: an enquiry into the origins of cultural change.

Cambridge: Blackwell Publishing, 1992.

HARVEY, D. Globalization and the "Spatial Fix". Geographische Revue, Wesel, p. 23-30, 2001.

HETTNER, A. O sistema das ciências e o lugar da Geografia. Geographia, Rio de Janeiro, v.2, n.3, p. 143-146, 2000.

HOLT GIMÉNEZ, E.; SHATTUCK, A. Food crises, food regimes and food movements: rumblings of reform or tides of transformation? The Journal of peasant studies, Hague, v. 38, n. 1, p. 109-144, 2011.

HUMBOLDT, A. VON. Cosmos. Ensaios de una descripcion física del mundo. Bruxelas: Eduardo Perié, 1875.

HUSSERL, E. A ideia da Fenomenologia. Lisboa: Edições 70, 1976.

KEPKIEWICZ, L. Understanding food sovereignty in Canada: settler colonialism and indigenous - settler alliances. In: DESMARAIS, A. A.; CLAEYS, P.; TRAUGER, A. (Orgs.). Public policies for food sovereignty: social movements and the State. New York: Routledge, 2017. p. 168-180.

LA BLACHE, P. V. Princípios de Geografia Humana. Lisboa: Cosmos, 1954.

LA VIA CAMPESINA. Tlaxcala: Declaração da Via CampesinaTlaxcala, 1996.

LACOSTE, Y. A Geografia - isso serve, em primeiro lugar, para fazer a guerra. São Paulo: Papirus, 1988.

LENCIONI, S. Região e Geografia. São Paulo: EdUSP, 1999.

LENIN, V. I. U. O desenvolvimento do capitalismo na Rússia. São Paulo: Abril Cultural, 1982.

LEVIEN, M. Gender and land dispossession: a comparative analysis. Journal of Peasant Studies, Hague, v. 44, n. 6, p. 1113-1136, 2017. https://doi.org/10.18356/886cb6f5-en

MANSFIELD, B. Wake up call: California drought \& B.C.' s food security. Vancouver: Vancity, 2014.

MARSDEN, T. From post-productionism to reflexive governance: Contested transitions in securing more sustainable food futures. Journal of Rural Studies, Aberystwyth, v. 29, n. January 2011, p. 123-134, 2013.

MASSEY, D. Concepts of space and power in theory and in political practice. Documents d'Anàlisi Geogràfica, Barcelona, n. 55, p. 15-26, 2009.

MAZOYER, M.; ROUDART, L. A History of World Agriculture: From the Neolithic Age to the Current Crisis. New York: Monthly Press Review, 2006.

MCMICHAEL, P. Development and social change : a global perspective. Thousand Oaks: Pine Forge Press, 2000.

MCMICHAEL, P. The power of food. Agriculture and Human Values, Dordrecht, v. 17, p. 21-33, 2003. https://doi.org/10.1023/A:1007684827140

McMICHAEL, P. Historicizing Food Sovereignty. Journal of Peasant Studies, Hague, v. 41, n. 6, p. 933 957, 2014. https://doi.org/10.1080/03066150.2013.876999

MCMICHAEL, P. Commentary: Food regime for thought. The Journal of Peasant Studies, Hague, v. 43, n. 3, p. 648-670, 2016. https://doi.org/10.1080/03066150.2016.1143816

MDA - MINISTÉRIO DO DESENVOLVIMENTO AGRÁRIO. Abordagem territorial do desenvolvimento : perspectivas e desafios a partir da experiência do Programa Territórios da Cidadania. Brasília, 2012.

MERLEAU-PONTY, M. Fenomenologia da percepção. São Paulo: Martins Fontes, 1999.

\begin{tabular}{llllll}
\hline Caminhos de Geografia & Uberlândia - MG & v. 19, n. 68 & Dez/2018 & p. 372-388 & Página 386
\end{tabular}


MONTEIRO, C. A.; CANNON, G. The impact of transnational " big food "' companies on the South : a view from Brazil. Plos Medicine, San Francisco, v. 9, n. 7, p. 1-5, 2012.

https://doi.org/10.1371/journal.pmed.1001252

MOREIRA, R. Para onde vai o pensamento geográfico? São Paulo: Contexto, 2006.

MOREIRA, $R$. Da região à rede e ao lugar: a nova realidade e o novo olhar geográfico sobre o mundo. etc. Revista de Ciências Humanas e Sociais, Rio de Janeiro,v. 1, n. 3, p. 44-70, 2007.

MOREIRA, R. Sociedade e espaço geográfico no Brasil. São Paulo: Contexto, 2011.

MURPHY, S. Expanding the possibilities for a future free of hunger. Dialogues in Human Geography, Kildare, v. 4, n. 2, p. 225-228, 2014. https://doi.org/10.1177/2043820614537166

OLIVEIRA, F. Elegia para uma re(li)gião. Sudene, Nordeste. Planejamento e conflitos de classe. Rio de Janeiro: Paz \& Terra, 1987.

PATEL, R. What does food sovereignty look like? Journal of Peasant Studies, Hague, v. 36, n. 3, p. 120, 2009.

PATEL, R. C. Food Sovereignty: power, gender, and the right to food. Plos Medicine, San Francisco, v. 9, n. 6, p. 1-4, 2012. https://doi.org/10.1371/journal.pmed.1001223

PAULA, N. M.; SANTOS, V. F.; PEREIRA, W. S. A financeirização das commodities agrícolas e o sistema agroalimentar. Estudos, Sociedade e Agricultura, Rio de Janeiro, v. 23, n. 2, 2015.

PORTO, S. I.; SOARES, E. S.; SOARES, J. F.; CRUZ, K. C. M. S.; VIEGAS, G. L.; VIANA, C. Programa de Aquisição de Alimentos (PAA): 10 anos de uma política pública múltipla e inovadora. In: MDS MINISTÉRIO DO DESENVOLVIMENTO SOCIAL E COMBATE À FOME (Ed.). PAA: 10 anos de aquisição de alimentos. Brasília: Secretaria Nacional de Segurança Alimentar e Nutricional/Secretaria de Avaliação e Gestão da Informação, 2014. p. 34-57.

RAFFESTIN, C. Por uma Geografia do poder. São Paulo: Ática, 1993.

RENTING, H.; MARSDEN, T. K.; BANKS, J. Understanding alternative food networks: Exploring the role of short food supply chains in rural development. Environment and Planning A, Londres, v. 35, n. 3, p. 393411, 2003.

RIBEIRO, A. C. T. Regionalização: fato e ferramenta. In: LIMONAD, E.; HAESBAERT, R.; MOREREIRA, R. (Orgs.). Brasil, século XXI - por uma nova regionalização?: agentes, processos e escalas. São Paulo: Max Limonad, 2004. p. 194-212.

RITTER, K. Comparative Geography. New York: American Book, 1865.

ROMAN-ALCALÁ, A. Occupy the farm : a study of civil society tactics to cultivate commons and construct food sovereignty in the United States. In: Food sovereignty: a critical dialogue (International Conference): Anais... New Haven: ISS-Agrarian, Food \& Environmental Studies (AFES), Initiatives in Critical Agrarian Studies (ICAS), Transnational Institute (TNI), Institute for Food and Development Policy/Food First, Land Deal Politics Initiative (LDPI), The Journal of Peasant Studies, 2013.

ROUTLEDGE, P. Critical geopolitics and terrains of resistance. Political Geography, Durhan, v. 15, n. 67, p. 509-531, 1996.

RUDOLPH, K. R.; MCLACHLAN, S. M. Seeking Indigenous food sovereignty: Origins of and responses to the food crisis in northern Manitoba, Canada. Local Environment, Boston, v. 18, n. 9, p. 1079-1098, 2013. https://doi.org/10.1080/13549839.2012.754741

SANTOS, M. Por uma Geografia nova. São Paulo: Hucitec, 1986.

SANTOS, M. Metamorfoses do espaço habitado. São Paulo: Hucitec, 1988.

SANTOS, M. O Dinheiro e o Território. Geographia, Rio de Janeiro, v. 1, n. 1, p. 7-13, 1999.

SANTOS, M. Por uma outra globalização: do pensamemto único à consciência universal. São Paulo: Record, 2000.

SANTOS, M.; SILVEIRA, M. L. Brasil: território e sociedade no século XXI. São Paulo: Record, 2001. SANTOS, M.; SOUZA, M. A. A.; SILVEIRA, M. L. Território: globalização e fragmentação. São Paulo: Hucitec, 2002.

\begin{tabular}{llllll}
\hline Caminhos de Geografia & Uberlândia - MG & v. 19, n. 68 & Dez/2018 & p. 372-388 & Página 387
\end{tabular}


SASSEN, S. Regulating immigration in a global age: a new policy landscape1. Parallax, London, v. 11, $\mathrm{n}$. 1, p. 35-45, 2005. https://doi.org/10.1080/1353464052000321083

SCHIAVONI, C. The global struggle for food sovereignty: from Nyéléni to New York. Journal of Peasant Studies, Hague, v. 36, n. 3, p. 682-689, 2009.

SHAW, D. J. World Food Security: A History since 1945. New York: Palgrava MacMillan, 2007. https://doi.org/10.1057/9780230589780

SIMON, G. A. Food Securit: definition, four dimensions, history. Roma: FAO, 2012.

SMITH, N. O desenvolvimento desigual. Rio de Janeiro: Bertrand Brasil, 1988.

SONNINO, R. Escaping the Local Trap: Insights on Re- localization from School Food Reform Escaping the Local Trap : Insights on Re-localization from. Journal of Environmental Policy \& Planning, Basel, v. 12, n. July 2011, p. 37-41, 2010.

STÉDILE, J. P.; CARVALHO, H. M. DE. Soberania alimentar: uma necessidade dos povos. 2011. Disponível em:<http://www.ecodebate.com.br/2011/03/25/soberania-alimentar-uma-necessidadedospovos-artigo-de-joao-pedro-stedile-e-horacio-martins-de-carvalho/>. Acesso em: 12 de nov. de 2015.

TRAUGER, A. Food sovereignty in international context: discourse, politics and practice of place. New York: Routledge, 2015. https://doi.org/10.4324/9781315764429

TRAUGER, A. Community based rights to food sovereignty: the case of the local and community selfgovernance ordinances in Maine, USA. In: DESMARAIS, A. A.; CLAEYS, P.; TRAUGER, A. (Orgs.). . Public policies for food sovereignty: social movements and the State. New York: Routledge, 2017. p. 53-70.

TROTSKY, L. A revolução permanente. 1985.

VAINER, C. B. Planejamento territorial e projeto nacional: os desafios da fragmentação. Revista Brasileira de Estudos Urbanos e Regionais, Curituba v. 9, n. 1, p. 09-23, 2007.

Van HOUTUM, H. The Geopolitics of Borders and Boundaries. Geopolitics, London, v. 10, n. 4, p. 672679, 2005. https://doi.org/10.1080/14650040500318522

VIEIRA, F. B. Via Campesina: um projeto contra-hegemônico? Via Campesina: um projeto contrahegemônico? Simpósio Lutas Sociais na América Latina. Anais...Londrina: Universidade Estadual de Londrina, 2008.

VINHA, J. F. DE S. C.; SCHIAVINATTO, M. Soberania alimentar e territórios camponeses: uma análise do Programa de Aquisição de Alimentos ( PAA ). Revista NERA, Presidente Prudente, n. 26, p. 183-203, 2015. WEKERLE, G. R. Food Justice Movements: Policy, Planning, and Networks. Journal of Planning Education and Research, Tallahassee, v. 23, n. 4, p. 378-386, 2004.

WITTMAN, H. Food Sovereignty a new rights framework for food and nature? Environment and Society: Advances in Research, Wageningen, v. 2, p. 87-105, 2011.

WITTMAN, H. From protest to policy: The challenges of institutionalizing food sovereignty. Canadian Food Studies, Ottawa, v. 2, n. 2, p. 174-182, 2015. https://doi.org/10.15353/cfs-rcea.v2i2.99

WITTMAN, H.; DESMARAIS, A. A.; WIEBE, N. Food sovereignty in Canada: creating just and sustainable food systems. Winnipeg: Fernwood Publishing, 2011.

Recebido em: 28/12/2017

Aceito para publicação em: 11/07/2018 